\title{
Neutrophilic Myelocyte Count
}

National Cancer Institute

\section{Source}

National Cancer Institute. Neutrophilic Myelocyte Count. NCI Thesaurus. Code C84823.

The determination of the number of neutrophilic myelocytes in a blood sample. 